Erikson, D. (1953). J. gen. Micrubiol. 8, 449-454.

\title{
The Reproductive Pattern of Micromonospora vulgaris
}

\author{
By DAGNY ERIKSON \\ Bacteriology Department, University of Aberdeen
}

\begin{abstract}
SUMMARY: The thermophilic actinomycete Micromonospora vulgaris resembles known mesophilic members of the genus Micromonospora in reproducing by means of small refractile spores borne singly on lateral branches of the vegetative mycelium. Its distinctive feature is the consistent production of a secondary aerial mycelium under optimal laboratory cultural conditions and in grass composts during the high temperature phase. This aerial mycelium is composed of abundantly branched, hydrophobic filaments which rapidly segment. The cells in these filaments may in turn give rise to similar refractile spherical spores borne singly on very short lateral branches. The reproductive pattern here described is one of the most complex yet known among the actinomycetes. It is thought that the aerial phase of development is intimately associated with the thermophilic nature of the organism.
\end{abstract}

When originally defining the genus Micromonospora, Orskov (1923) described the type-species, $M$. chalceae, as completely devoid of aerial mycelium, reproduction taking place by means of small spherical to oval spores borne singly on the distal ends of short lateral branches of the vegetative mycelium. Erikson (1949) confirmed the essential validity of this description, and stated 'The few instances of aerial mycelium that have been reported...(since)... are all of the nocardial type, a sparse development of mostly unbranched and undivided filaments. Such development is spasmodic and infrequent and does not represent a sporogenous phase.' This view was in accordance with the work of Waksman, Umbreit \& Cordon (1939) on the thermophilic actinomycetes which occur in dunged composts and soils. Thus, although they noted that their strains of $\boldsymbol{M}$. vulgaris differed from the mesophilic strains described by Jensen (1930) by the appearance of a slight aerial mycelium on certain media, they considered this of no significance and stated that 'the aerial mycelium, though present, is usually rudimentary, rarely exhibiting the tangled network of strands typical of Actinomyces species'. The observation of Miehe (1907) and other early workers that the white lime-like coating on hot compost heaps was caused by thermophilic actinomycetes was re-emphasized by Forsyth \& Webley (1948). Erikson (1952) explained this appearance as due to the very abundant production of an aerial mycelium which was hydrophobic and gave rise to heat-resistant spores. The brief description of the development of $\boldsymbol{M}$. vulgaris which follows is based on the almost continuous observation, during a period of two to three years, of seven strains, six, $M, D, F, D_{3}$, $\mathrm{B}_{2}, \mathrm{~B}_{4}$, isolated from composts, and a seventh, $\mathrm{H}$, isolated from canned ham by Dr Heller.

\section{METHODS}

During experiments detailed elsewhere (Erikson, 1952) spore suspensions of suitable concentrations were continually being prepared. These were streaked on blocks of agar for slide cultures, or on strips of cellophan laid over the 
water-agar medium. In other instances suspensions of spores in fresh liquid medium were run under the surface of sterile cover-slips, which were supported by discontinuous strips of agar. The practice of inverting a cover-slip over the inoculum directly on to a block of agar does not allow sufficient aeration for the development of $M$. vulgaris; similar drawbacks apply to hanging-drop cultures. The best preparations were obtained on cellophan which had been sterilized in the liquid medium and then incubated over medium of the same composition solidified by agar. An environment of $100 \%$ humidity was provided by incubating the slide-cultures in metal slide boxes with close-fitting lids which were lined with sterile moistened absorbent cotton-wool. Incubation was at $55^{\circ}$ or $60^{\circ}$.

In connexion with other work there was available a constant supply of surface and bottom growth from liquid cultures in small stoppered bottles and larger flasks; of spreading coherent growth on cellophan strips and circles; of colonies of all sizes and ages on agar plates and roll tubes. Sometimes a single giant colony, representing the survivor of a heat-testing experiment, was available. All such material was examined in the living state.

The CPS medium described earlier (Erikson, 1952; nutrient broth supplemented with casein digest, pea extract and starch) was used consistently. A simpler basal medium containing $5 \%(\mathrm{v} / \mathrm{v})$ enzymic digest of casein and Czapek mineral salts was also used, to which various additions were made, e.g. $1 \%$ starch, maltose, sucrose or mannitol; $0 \cdot 01-0.1 \%$ yeast extract (Difco, Oxoid or Yeastrel); 5-10\% (v/v) fresh grass juice, Waring-blended grass or compost extract; $5-15 \%(\mathrm{v} / \mathrm{v})$ rabbit dung extract (made by autoclaving 1 part rabbit dung with 5 parts water); or sterilized compost.

\section{RESULTS}

\section{Vegetative mycelium}

The indispensable primary method of propagation of this organism, as of other actinomycetes, is through the proliferation of a ramified mycelium. When the submerged hyphal growing tips of an active young culture on an agar medium are removed to a suitable liquid medium, a proportion of these filaments will elongate, branch, and in 12-18 hr. fill the bottom of the container with small puffball colonies. The proportion of dismembered filaments capable of renewed life when transplanted to fresh medium is low. Very few filaments, fragmented and isolated for slide culture observation, can be noted as actually growing in any given experiment. Massive seedings are required, especially when growth on solid media is desired.

The vegetative mycelium of $M$. vulgaris differs from that of the mesophilic micromonosporas chiefly in those respects which are distinctive of thermophilic bacteria in general : $(a)$ a greater degree of elongation of the cells, which in this type of organism leads to wider spacing between the branches and in consequence a diffuse form of growth (Pl. 1, fig. 1); (b) a more rapid disintegration of the cells, which may take place in 1-2 days rather than in the 1-2 months of the long-lived mesophiles. The rate of disintegration, however, varies 
considerably according to the experimental conditions, especially as concerns degree of aeration, and the nature of the substrate and of inoculum employed. Thus, the puffball growth at the bottom of static liquid CPS medium commonly begins to segment and to decay within 1-2 days (cf. the lack of measurable oxygen uptake of this material; Erikson \& Webley, 1953), and as a rule has autolysed within a week. The vegetative mycelium which spreads over the surface of cellophan sheet laid on CPS agar may still be structurally intact on the second day, even after the development of the aerial mycelium (Pl. 1, fig. 2). With a similar degree of aeration on a less rich medium, e.g. Czapek salts containing $5 \%(\mathrm{v} / \mathrm{v})$ casein digest $+1 \%(\mathrm{w} / \mathrm{v})$ maltose and $0.01 \%(\mathrm{w} / \mathrm{v})$ yeast extract, the life of the vegetative mycelium as a whole may be prolonged for several days.

\section{Sporulation of the vegetative mycelium}

The sporulation of the vegetative mycelium differs a little from that already described for the mesophilic species. On first isolation two strains $\left(\mathrm{D}_{3}\right.$ and $\mathbf{B}_{2}$ ) showed a tendency to produce spores mainly in clusters (see Pl. 1, fig. 3), especially at $\mathbf{5 5}^{\circ}$ and on compost-containing media. On further cultivation it was found that, as with the mesophilic $M$. chalceae, "the regular rule is single terminal spores, but any strain may show in the same field two, three, or more spores in close juxtaposition or in Botrytis-like clusters' (Erikson, 1941). The spores of the thermophilic strains also have the light-scattering properties characteristic of the genus. This intense degree of refractility renders the mature spores dazzling in darkground preparations, and causes them to appear as dense, opaque, spherical bodies in phase-contrast views (Pl. 1, fig. 2). Only the immature spores stain readily with the usual stains. Gray's spore stain is useful in demonstrating the older spores, which rapidly break loose from the parent branches. They are not acid fast.

Sporulation is not accompanied by a change in pigmentation as is the case of the mesophilic $M$. chalceae whose pink-orange vegetative mycelium turns glistening brown-black as the superficial spore layer is formed. The growth of M. vulgaris is colourless throughout.

\section{Aerial mycelium}

Aerial filaments arise by monopodial branching of vegetative hyphae. In general the aerial filaments are slightly wider than the vegetative hyphae, as is usual with the aerial mycelium of most mesophilic streptomycetes. The aerial filaments of $\boldsymbol{M}$. vulgaris rapidly branch to form an elaborately interwoven hydrophobic superstructure above the vegetative mycelium (Pl. 1, fig. 2). This aerial felt stains with Sudan Black and Sudan IV while the vegetative mycelium remains unstained. Segmentation of the aerial mycelium takes place within the first $18 \mathrm{hr}$. on most media, and can be seen very clearly by means of a phase-contrast microscope, even with a low-power objective (Pl. 1, fig. 4). 


\section{Sporulation of the aerial mycelium}

Only single lateral spores are produced, at intervals, along these multicellular and often very long filaments ( $\mathrm{Pl}$. 1, fig. 5). These aerial spores are easily detached, usually spherical when mature, and very refractile. There seems little morphological difference between such aerially borne spores and those produced by the vegetative mycelium in static liquid cultures. It is the aerial spores which, in the tests so far carried out, have exhibited heat resistance. But it is difficult to obtain spores from vegetative mycelium alone in such quantities as are yielded by aerial mycelium.

\section{Germination of spores}

All spores germinate by one to four germ-tubes. The degree and speed of branching thereafter displayed depend upon the nature of the medium and other conditions of growth. Thus, where the new growth is in continuous contact with an adequate medium (as in liquid culture, on the surface of moist agar or on moistened cellophan overlying agar) it develops a mycelium composed of very long filaments with more or less regular branching (cf. Pl. 1, fig. 1, also Fig. 24 of Waksman et al. 1939). But where the supply of nutrients is locally restricted, as when a suspension of spores in broth is poured along the undersurface of a cover-slip placed at an angle over discontinuous agar blocks, it is possible to see the 'scrolls' and 'loops', which result from the elongation unaccompanied by lateral branching, of the filamentous growth, following the movements of moisture on the glass (Pl. 1, fig. 6; also compare similar patterns described by Klieneberger-Nobel, 1947, for mesophilic streptomycetes).

\section{DISCUSSION}

Compared with eubacteria, actinomycetes in general are slow of development. This is true even of the organisms which are thermophilic as in the present instance. Thus the thermophilic sporing bacilli commonly encountered in the primary isolations from the composts had completed their full development and were passing into decline before the actinomycete $\boldsymbol{M}$. vulgaris had produced its aerial mycelium. This device of producing a secondary aerial mycelium, capable both of further growth and of producing spores, more than doubles the expected active life of a mycelial organism at elevated temperatures.

The observation (Erikson \& Webley, 1953) that the aerial mycelium has on the whole a higher oxygen uptake at $60^{\circ}$ than has the vegetative mycelium is another expression of the fact that $\boldsymbol{M}$. vulgaris is successfully adapted to existence in the high temperature phase of vegetable composts. In competition with the more rapidly multiplying bacilli, the vegetative filaments of $M$. vulgaris would probably be at a disadvantage in obtaining sufficient space and nutrients for good growth within the films of moisture adhering to the compost fibres. Sufficient moisture is essential for vegetative growth. Examination of the compost fibres reveals a very loose straggling growth of fine 
filaments with occasional portions densely sporulated. A moderately profuse mycelial development is found only where the aerial filaments branch into air spaces between the fibres.

The media described for the cultivation of $M$. vulgaris all contain complex nitrogenous substances. Two or three of the isolates when first purified were unable to produce any aerial mycelium on artificial media until these had been supplemented with rabbit dung or compost extract. It therefore seems likely that in compost heaps the first production of aerial mycelium by $\boldsymbol{M}$. vulgaris has some connexion with the availability of suitable bacterial and vegetable breakdown products. The hydrophobic wall of the aerial filaments may also serve as a barrier to the passage of noxious substances, which, in the saturated humid atmosphere generally obtaining throughout the compost, might otherwise be able to penetrate the cells; or again it might protect against occasional desiccation in the superficial layers. The repetition by the aerial mycelium of the type of sporulation which characterizes the vegetative mycelium, namely, the production of single lateral spores, emphasizes this distinctive feature of the genus, which is of considerable systematic importance. The thermophilic $M$. vulgaris thus possesses properties that separate it from mesophilic species of the same genus; it appears to have one of the most complex reproductive patterns of any actinomycete yet studied.

This work was done by the author as a member of the scientific staff of the Agricultural Research Council, who also provided an expenses grant. I wish to thank Prof. J. Cruickshank for the hospitality of his department; Mr Jabez Bruce for the phase-contrast photographs; and Miss Mildred MacKay for technical assistance.

\section{REFERENCES}

Erikson, D. (1941). Studies on some lake-mud strains of Micromonospora. J. Bact. 41, 277.

Erikson, D. (1949). The morphology, cytology, and taxonomy of the actinomycetes. Ann. Rev. Microbiol. 3, 23.

Erikson, D. (1952). Temperature/growth relationships of a thermophilic actinomycete, Micromonospora vulgaris. J. gen. Microbiol. 6, 286.

Erikson, D. \& Webley, D. M. (1953). The respiration of a thermophylic actinomycete, Micromonospora vulgaris. J. gen. Microbiol. 8, 455.

Forsyth, W. G. D. \& Webley, D. M. (1948). The microbiology of composting. II. A study of the aerobic thermophilic bacterial flora developing in grass composts. Proc. Soc. appl. Bact. 3, 34.

Jensen, H. L. (1930). The genus Micromonospora Ørskov-a little known group of soil micro-organisms. Proc. Linn. Soc., N.S.W. 55, 231.

Klieneberger-Nobel, E. (1947). The life cycle of sporing Actinomyces as revealed by a study of their structure and septation. J. gen. Microbiol. 1, 22.

Mrene, H. (1907). Die Selbsterhitzung des Heues. Jena: G. Fischer.

Ørskov, J. (1923). Investigations into the morphology of the ray fungi. Copenhagen: Levin and Munksgaard.

Waksman, S. A., Umbreit, W. W. \& Cordon, T. C. (1939). Thermophilic actinomycetes and fungi in soils and in composts. Soil Sci. 47, 37 . 


\section{EXPLANATION OF PLATE}

Fig. 1. Diffusely branching vegetative mycelium, 2 days old, on cellophan over CPS agar. Note single incipient lateral spore at arrow. Phase contrast. $(\times 600$. $)$

Fig. 2. Another portion of the same growth as Fig. 1, showing abundant development of raised aerial mycelium with considerable spore production. Spores appear round, dense, opaque. Phase contrast. $(\times 750$.)

Fig. 3. Strain $\mathbf{B}_{2}$, growing on cellophan over sterile compost, 1 day old. Long vegetative filament in centre field, showing cluster type of sporulation. Stained by Jones Mollison technique. $(\times \mathbf{5 5 0}$. $)$

Fig. 4. Strands of branching, segmented, aerial mycelium at margin of colony on CPS agar plate; 2 days old. Phase contrast. $(\times 200$.)

Fig. 5. Higher magnification of portion of same growth as in Fig. 4, showing cellular contents of aerial filaments and single lateral spores. Spores appear very dense. Phase contrast. $(\times \mathbf{1 8 0 0}$.

Fig. 6. $18 \mathrm{hr}$. growth produced when a spore suspension in broth was poured along the under-surface of a cover-slip inclined at an angle over CPS agar strips. Note 'scroll' formed by 4-5 filaments elongating in one channel; germinating spore giving rise to 'Ioop' as direction of new filaments shifts slightly with varying food supply. Arrow marks ungerminated spore. Fixed with osmic acid, stained with Gray's spore stain. ( $\times$ 1500.) Photograph by Miss Irene Taylor.

(Received 5 December 1952) 
Journal of General Microbiology, Vol. 8, No. 3

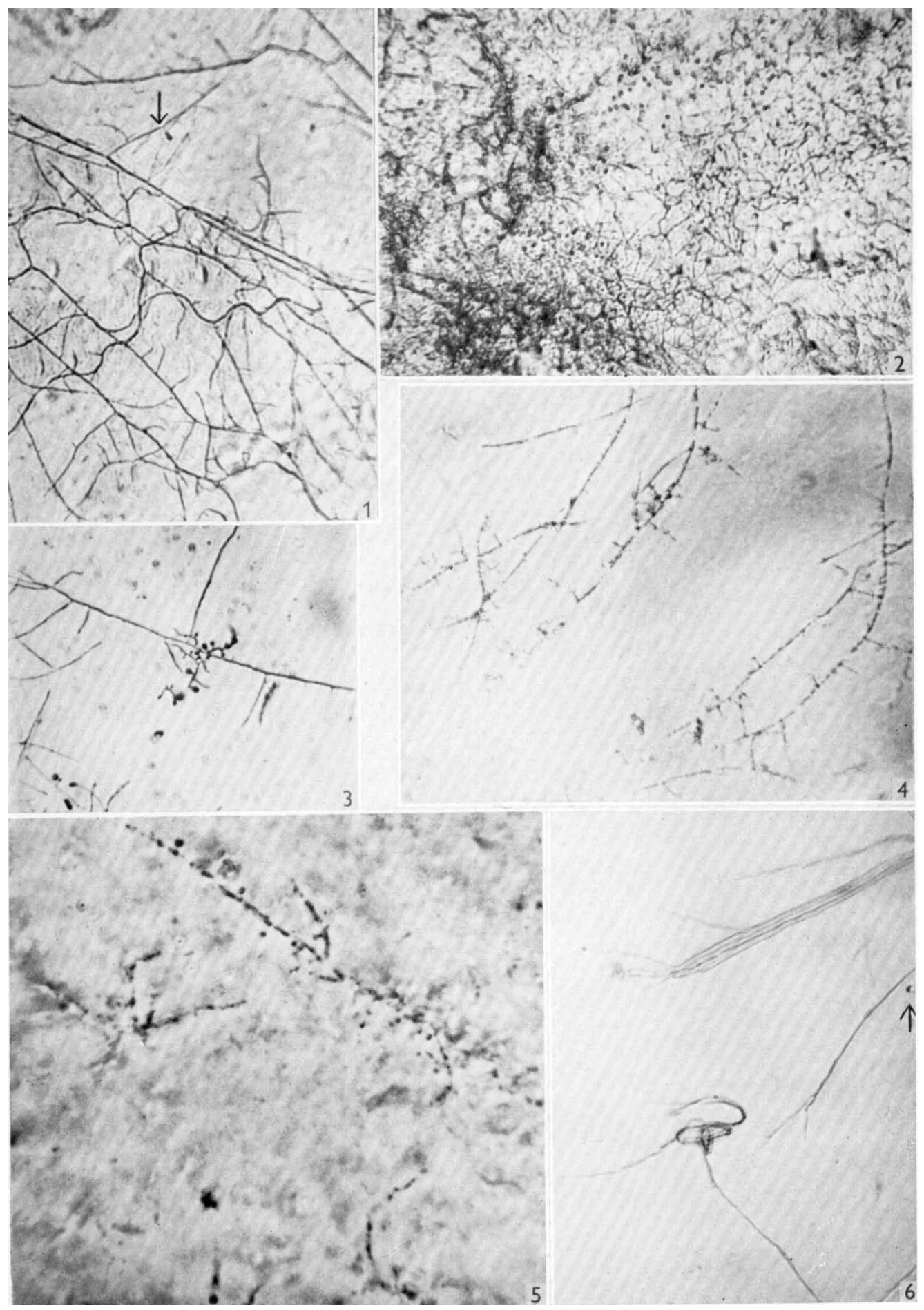

D. Erikson-Reproduction of Mitrononospora velgaris. Plate 1 